\title{
Spatial Visualization Ability and Learning Style Preference Assessment Among Construction Related Undergraduate Engineering and Technology Students
}

\section{Richelle Fosu, Purdue University, West Lafayette}

Richelle Fosu is a PhD Fellow/Candidate in the Computer Graphics Technology department at Purdue University. Her specialization is in Building Information Modeling. Richelle Fosu has a BS in Electrical Engineering and Computer Science from Jacobs University, Bremen Germany; and a MS in Computer Graphics Technology from Purdue University. Her research interests include Building Information Modeling, Spatial Visualization and technology enhanced learning.

\section{Karthik Sukumar, Purdue University}

Dr. Patrick E. Connolly, Purdue University, West Lafayette

Dr. Patrick Connolly is a professor and department head of the Department of Computer Graphics Technology in the College of Technology at Purdue University. He has extensive experience in the aerospace design and CAD/CAE software industries, and has been serving in higher education for almost twenty years. Dr. Connolly has a BS degree in Design and Graphics Technology and an MS in Computer Integrated Manufacturing from Brigham Young University, and a PhD in Educational Technology from Purdue University. His research interests include spatial ability development, virtual and augmented reality applications, product data and lifecycle management, and innovative classroom methodologies. 


\title{
SPATIAL VISUALIZATION ABILITY AND LEARNING STYLE PREFERENCE ASSESSMENT AMONG CONSTRUCTION RELATED UNDERGRADUATE ENGINEERING AND TECHNOLOGY STUDENTS.
}

\begin{abstract}
This research paper presents an investigation into the relationship between learning style preferences and spatial ability levels of students within construction related majors in engineering and technology. This study used a quantitative approach of data collection, with the instruments for data collection being the Purdue Spatial Visualization test (PSVT) and the Felder-Soloman Index of Learning Styles (ILS). The relationship between the identified learning styles of the participants and their visualization skills was explored, in order to better understand if higher/lower spatial abilities had any correlation with an individual's learning style preference.
\end{abstract}

\section{$\underline{\text { Introduction }}$}

Spatial ability has been a significant topic of research since the 1920 's ${ }^{1}$. Spatial ability is defined as the ability to mentally manipulate $2 \mathrm{D}$ and $3 \mathrm{D}$ objects, comprehend how elements are arranged within a visual stimulus and also as the ability to remain unconfused by the changing orientation within which objects are presented ${ }^{2-3}$.

Spatial ability has been primarily categorized into three essential factors - namely: visualization, mental rotation and spatial orientation. Each of these factors concentrate on specific spatial skill. Several instruments in the form of tests have been developed over the years in order to measure the extent of these skills. Every instrument developed has been geared towards measuring different components of spatial ability, such as the Vandenberg's mental rotation test ${ }^{4}$ for mental rotation tasks; and the paper folding and surface development tests ${ }^{5}$ for visualization tasks. Visualization has been defined as the ability to conceptualize when there is some movement or change in the overall configuration or the parts of the configuration of an object ${ }^{6}$. Spatial visualization skills are considered vital in STEM fields, notably in engineering ${ }^{7-9}$. The extent of these skills vary in every individual, and have been shown to be affected by factors such as gender, experience and environment.

Learning styles have been defined as the preferences with respect to the methods of perception, analysis and absorption of information ${ }^{10}$. Several constructs and instruments have been developed to specifically label and categorize the unique modes of learning. A report from Coffield ${ }^{11}$ identified 71 models of learning styles - most of which were adaptations of others or were developed on small homogenous samples, and were thus not widely accepted. Curry ${ }^{12}$ noted that there was a great deal of overlap in concepts and meanings of terminology within the vast myriad of proposed models and characterized 9 of the major learning style models into a 3 tiered onion-like structure. These tiers were labeled instructional preference, e.g. Learning preference inventory; cognitive personality e.g. MBTI; information processing e.g. Kolb learning model ${ }^{12}$. 
Other examples of learning style models and indexes are the Gregorc Style Delineator ${ }^{13}$ with the dimensions of concrete, abstract, sequential or random; Herrmann's Brain Dominance Instrument $^{14}$, which categorizes learners as theorists, organizers, innovators, and humanitarians; Dunn and Dunn's Learning Styles Inventory ${ }^{15}$, which concentrates on visual, auditory, tactile, and kinesthetic processing ${ }^{16}$. Learning preferences have been extensively studied in the past, in an attempt to enhance student learning and effective teaching ${ }^{17}$. These various tests and indexes have been used as a basis to evaluate learning and teaching styles ${ }^{18,19}$, in order to propose changes to traditional classroom practices to improve student learning ${ }^{20,21}$; diversify teaching approaches and assessment methods ${ }^{22}$; enhance online learning experiences ${ }^{23}$; and to determine links between learning styles and performance ${ }^{24,25}$.

For this research, the Felder-Soloman Index of Learning Styles (ILS), as well as the Purdue Spatial Visualization test (PSVT) were used as the instruments of measure to determine the students learning style preferences and spatial visualization skills respectively.

The Purdue Spatial Visualization Test (PSVT) was created in 1977 by Richard Guay ${ }^{26}$. The PSVT consists of a paper based test with three sections that address the constructs of visualization, mental rotation and spatial orientation. These test the ability of a student to visualize folding two-dimensional patterns into three dimensional objects; visualize the rotation of 3 dimensional objects; and visualize how three dimensional object look like when viewed from different positions respectively ${ }^{26}$. The PSVT was used because it measures an individual's spatial ability over the three primary spatial factors as explained earlier. This provides a distinct advantage compared to other spatial tests.

The ILS is an instrument created by Felder and Soloman in order to classify the dominant preference engineering students showed in one dimension between each of the following pairs of the learning style model proposed by Felder and Silverman in $1988^{28}$. Sensing vs Intuitive; Visual vs Verbal; Active vs Reflective; Sequential vs Global. These dimensions in the ILS draw from other well-known learning style models such as the Myers Briggs Type Indicator (MBTI) and the Kolb learning style index ${ }^{27}$. The ILS has a substantial history of use and has been proven to provide consistent and valid results in numerous evaluative studies ${ }^{27-31}$. Reliability tests yielded Cronbach alpha results greater than 0.5 and consistent in all the ILS scales; while Pearson's correlation and factor analysis tests conducted also indicated that the different dimensions were indeed distinct - with a mild association found between the sequential global and sensing initiative scales ${ }^{26,29}$. Testing in various samples over time also showed support for the notion that the constructs being assessed by the ILS were valid ${ }^{28,30,31}$.

The ILS dimensions can be described as follows: Active (ACT) learners - problem solvers, who need to apply or discuss in order to learn; Reflective (REF) learners - learners who need to think material through completely in order to learn; Sensing (SEN) learners - learners who appreciate factual information and learn best through hands on experience; Intuitive (INT) learners learners who prefer to discover possibilities, are innovative and able to grasp abstract concepts ; Verbal (VRB) learners - learners who prefer written or spoken explanations in order to learn; Visual (VIS) learners - learners who prefer demonstrations or pictorial representation of 
material; Sequential (SEQ) learners - learners who prefer logical linear paths to learning; Global (GLO) learners - learners who think holistically and grasp the bigger picture. ${ }^{29,17}$

Independently, spatial skills and learning styles have been linked with the ability of students to do well in various fields ${ }^{32}$. High spatial ability would infer that an individual would have a better mental cognition, while the tailoring of curriculum to suit the needs of a student's learning style would typically result in better outcomes ${ }^{12}$. However, it is not quite clear whether a direct link between a students' learning preference and their spatial ability exists. This research is aimed at determining the spatial ability level and learning style preferences of a select group of students; and also assessing whether or not a student's spatial abilities have any relation to their learning style preference - specifically within the realm of construction related majors in engineering and technology.

\section{Methodology}

This study was administered during the fall semester in a University's 100-level introductory graphics and visualization course, using a quantitative approach of data collection. 192 of the total 204 students in the course participated voluntarily in this study. During lab session, participants were administered the online ILS test, followed directly by the paper based PSVT. This was done for each of the 9 sections in the class, during the first week of classes - prior to the onset of any formal lessons related to spatial visualization in the class.

The students comprised of 51 Freshmen (26\%), 128 Sophomores (67\%) and 13 Juniors (7\%), and were primarily from construction related majors - i.e., 73 Civil Engineering (38\%), 66 Building Construction Management Technology (34\%), 35 Construction Engineering Management (18\%) - as well as 13 First Year Engineering students (7\%), as depicted in figure 1. The remaining participants were undecided at the time of the study.

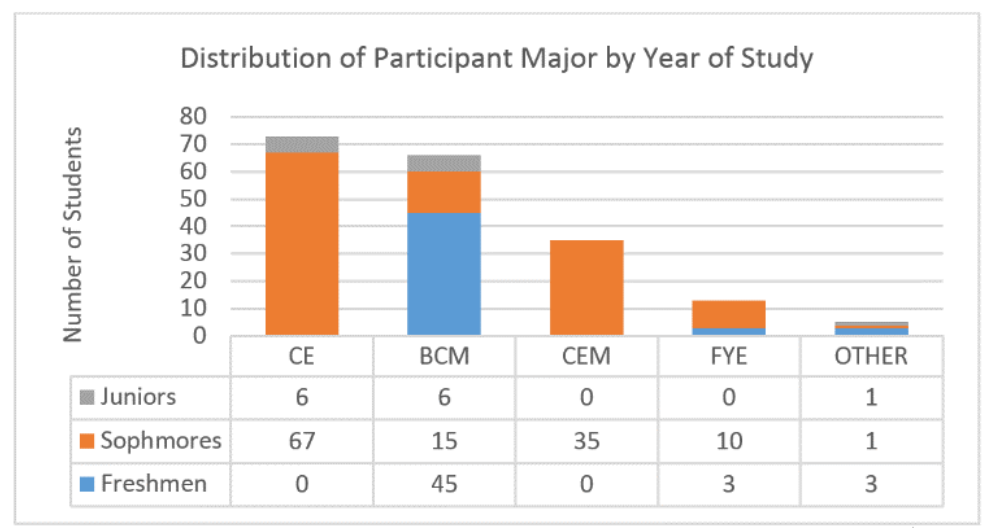

Fig 1. Distribution of student year of study by major

There were 43 females out of the 192 participants; as well as 28 participants out of the 192 who reported having prior experience with spatial visualization - through previous training in high school drafting/design courses and tests (20); interaction with video games (1); use of maps and 
life experiences with building (2); or other visualization courses offered in previous semesters (5).

Participant responses were recorded from each of the tests, and grouped based on their spatial ability level as well as on their learning style preference on the ILS index. Their spatial ability levels were rated low (for scores between 0-69\%), and high (for scores between 70-100\%), while the learning style preferences were branched out into all 16 possible combinations of the ILS grouping, as detailed in the table 1.

Table 1. ILS Dimension Groupings

\begin{tabular}{|c|c|c|c|}
\hline REF/INT/VRB/GLO & REF/SEN/VRB/SEQ & ACT/INT/VRB/SEQ & ACT/SEN/VRB/SEQ \\
\hline REF/INT/VRB/SEQ & REF/SEN/VRB/GLO & ACT/INT/VIS/GLO & ACT/SEN/VIS/GLO \\
\hline REF/INT/VIS/GLO & REF/SEN/VIS/GLO & ACT/INT/VIS/SEQ & ACT/SEN/VIS/SEQ \\
\hline REF/INT/VIS/SEQ & REF/SEN/VIS/SEQ & ACT/INT/VRB/GLO & ACT/SEN/VRB/GLO \\
\hline
\end{tabular}

\section{$\underline{\text { Results and Analysis }}$}

The data collected was statistically analyzed using descriptive statistics as well as inferential statistics using the Pearson's correlation coefficient, $t$ - test and ANOVA. Due to the varying sample sizes of the groupings, the folded $\mathrm{F}$ test for equality of variances was run on the data. It yielded a p-value of 0.2851 , indicating that the assumption of equal variances did not hold and the pooled variance could not be used for the calculations of the data. A basic t-test could not be used as a result of the unequal sample sizes and variances. Thus, the Welch-Satterthwaite approximation of the standard errors was used in the calculations instead, in order to account for the imbalance in sample sizes. These approximations obtained were then used in the subsequent (Welch) t-tests performed throughout the analysis.

\section{Overview of PSVT Scores Distribution}

When grouped by total test scores, it was found that 55\% (106) of the students scored above $70 \%$ on the PSVT - and were thus considered to have high spatial visualization skills; while 45\% (86) of the students scored below $70 \%$ on the PSVT - and were thus considered to have low spatial visualization skills. This information was then broken down by major - i.e., Building Construction Management Technology (BCM), Civil Engineering (CE), Construction Engineering Management (CEM), First Year Engineering (FYE) - as can be seen in figure 2. 


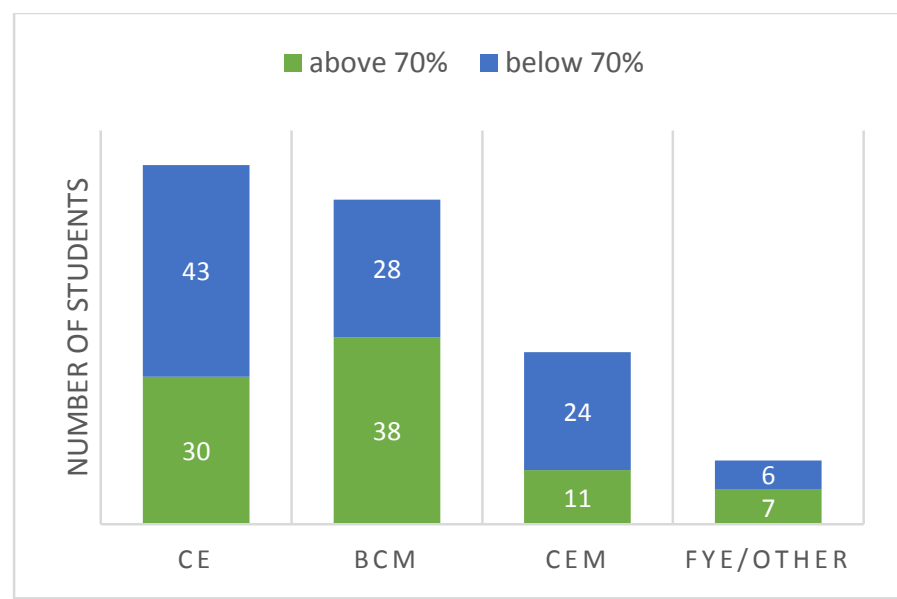

Fig 2. Distribution of students with high and low spatial ability by major

The mean PSVT scores by major were calculated and run through an ANOVA. The results showed a normal distribution of the data, and resulted in a p-value $<0.001$ thus rejecting the null hypothesis of equal means.

Table 2. ANOVA results on PSVT scores by major

\begin{tabular}{|l|l|l|l|l|}
\hline Factor & $\mathrm{N}$ & Mean & STDev & $95 \%$ CI \\
\hline CE & 73 & 27.192 & 6.42 & $(25.621,28.762)$ \\
\hline BCM & 66 & 22.803 & 1.244 & $(21.151,24.455)$ \\
\hline CEM & 35 & 27.83 & 6.66 & $(25.56,30.10)$ \\
\hline FYE/OTHER & 18 & 28.06 & 6.92 & $(24.89,31.22)$ \\
\hline
\end{tabular}

After running the 2 sample t-tests, no significant difference was found between CE, CEM and FYE/OTHER. However, a p-value < 0.01 obtained when the BCM student scored were tested with, CE CEM and FYE/OTHER indicating that the students in BCMs performance was significantly worse that the other majors, as is evident in Figure 3.

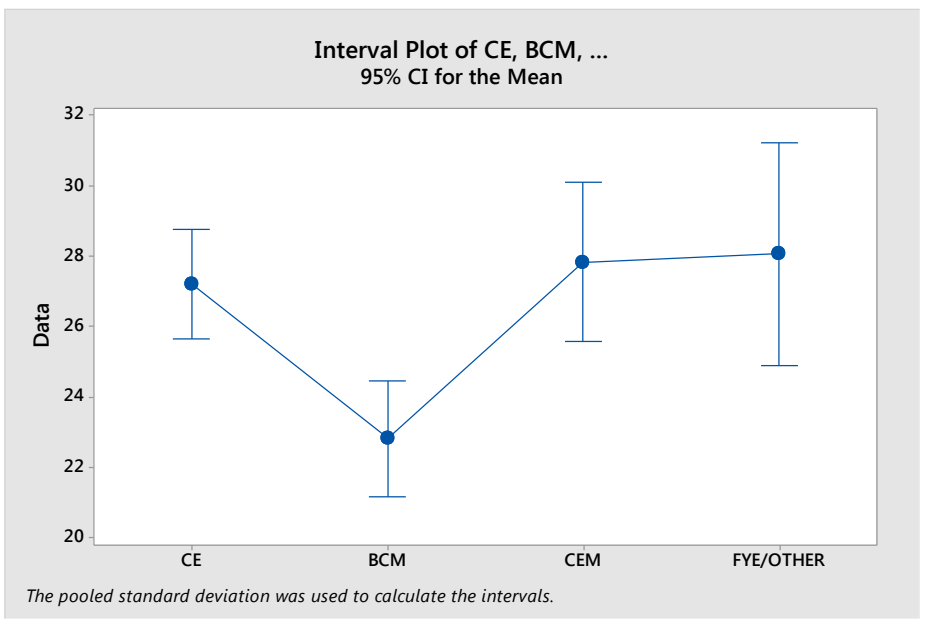

Fig 3. Plot of PSVT score means by major

$\underline{\text { Overview of ILS Results }}$ 
Observing each dimension on its own in figure 4, it was found that generally, the majority of the students had the preference of Active (ACT) over Reflective (REF); Sensing (SEN) over Intuitive (INT); Visual (VIS) over Verbal (VRB); and Sequential (SEQ) over Global (GLO).

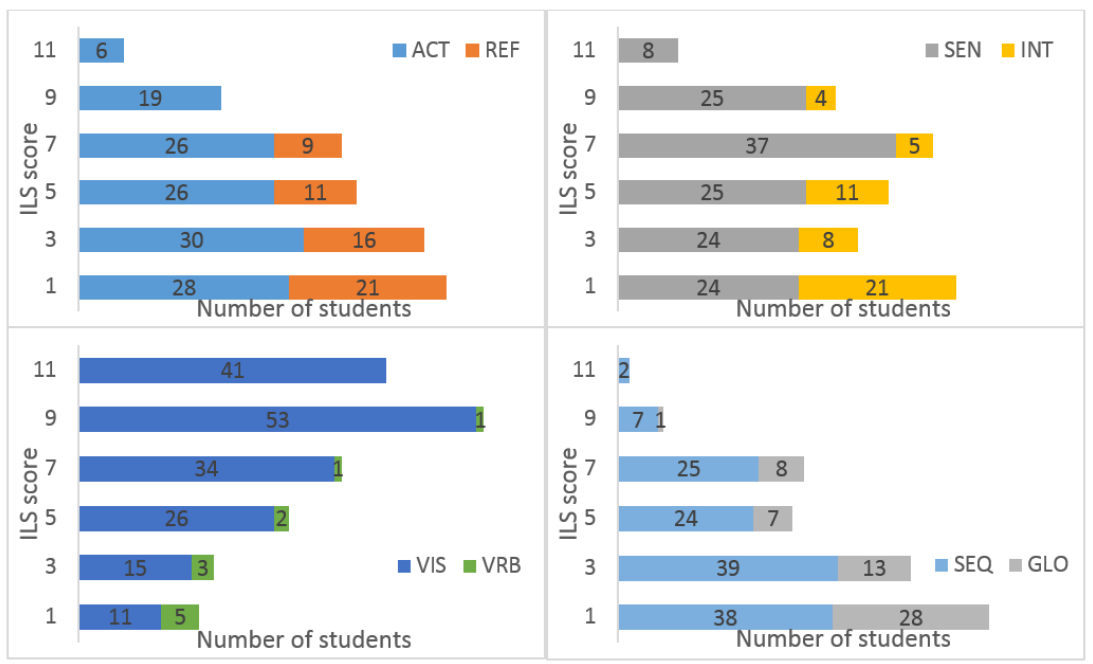

Fig 4. Distribution of students by learning style dimension

This is further reinforced in figure 5, when observing the number of students in each group combination of the dimensions. It was found again, that the majority of students $(38 \%)$ belonged to the ACT/SEN/VIS/SEQ group, followed by the REF/SEN/VIS/GLO group (17\%). The $\mathrm{ACT} / \mathrm{INT} / \mathrm{VRB} / \mathrm{GLO}$ group was not represented in the students sampled.

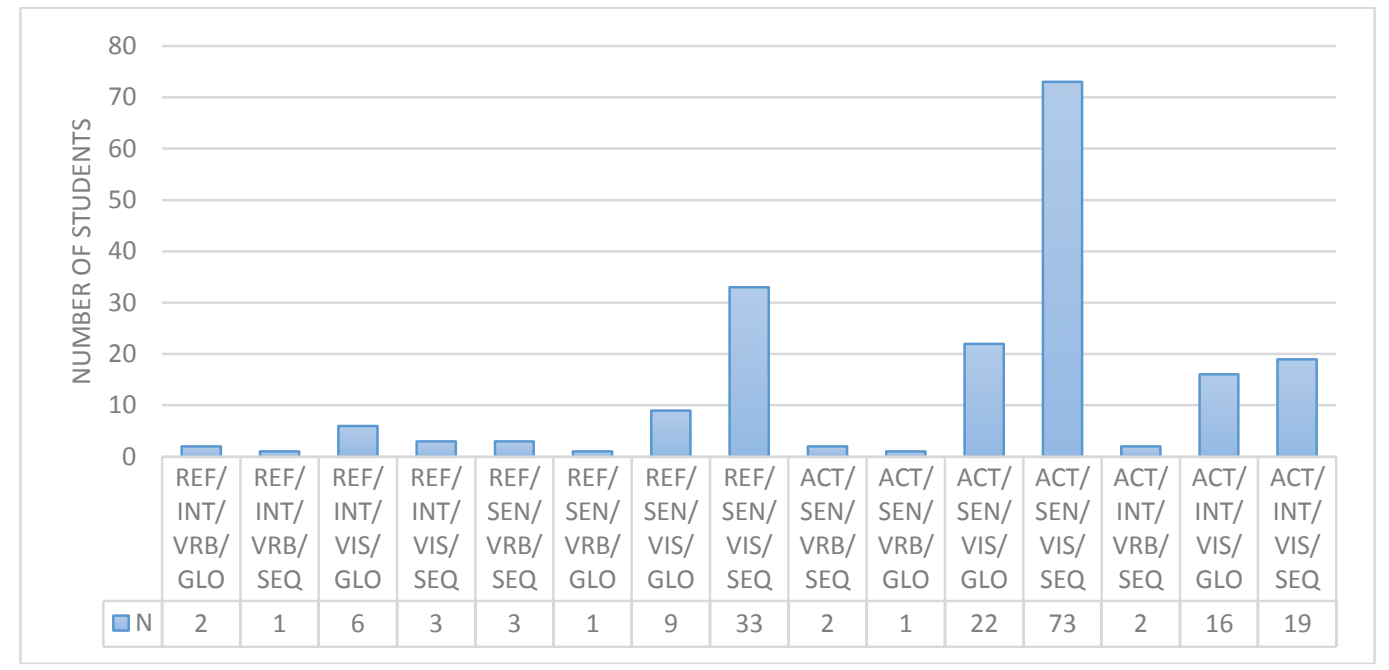

Fig 5. Distribution of all students by ILS dimension groupings

Scores grouped by ILS and major

Figure 6 displays the distribution of students - divided by major - for one dimension or the other. Again the ACT/SEN/VIS/SEQ preference can be seen in each of the majors represented. 


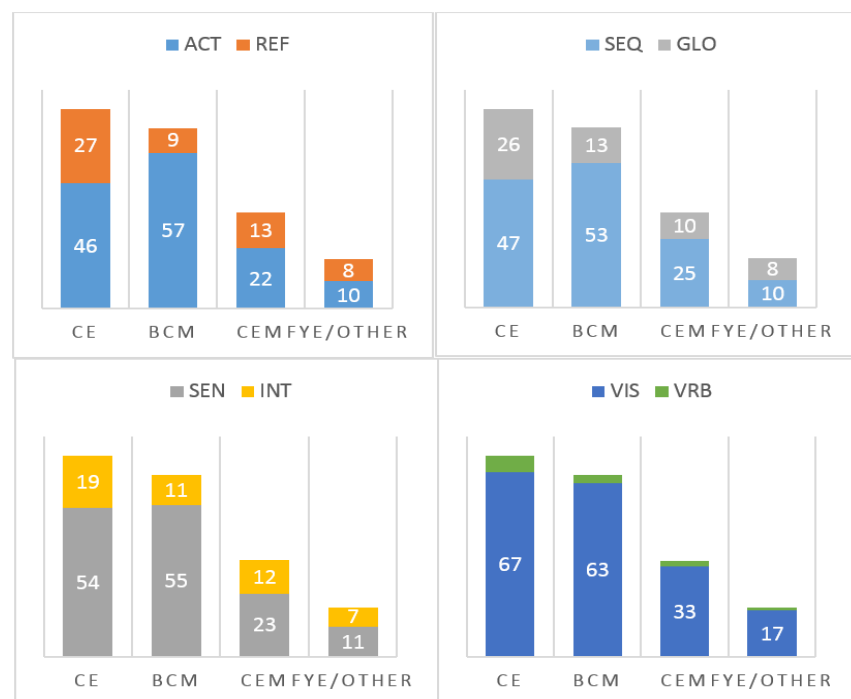

Fig 6. Distribution of students per major by learning style dimension

The ACT/SEN/VIS/SEQ group had the maximum number of students who did well on the PSVT. From the group itself, CE students were in the majority. Similarly, the ACT/SEN/VIS/SEQ group had the maximum students who had a lower spatial ability. BCM students were in a majority from this group. Figures 7 and 8 showcase the data broken down by ILS dimension grouping as well as by PSVT performance (whether above $70 \%$ - for high spatial ability; or below $70 \%$ - for low spatial ability), by major.

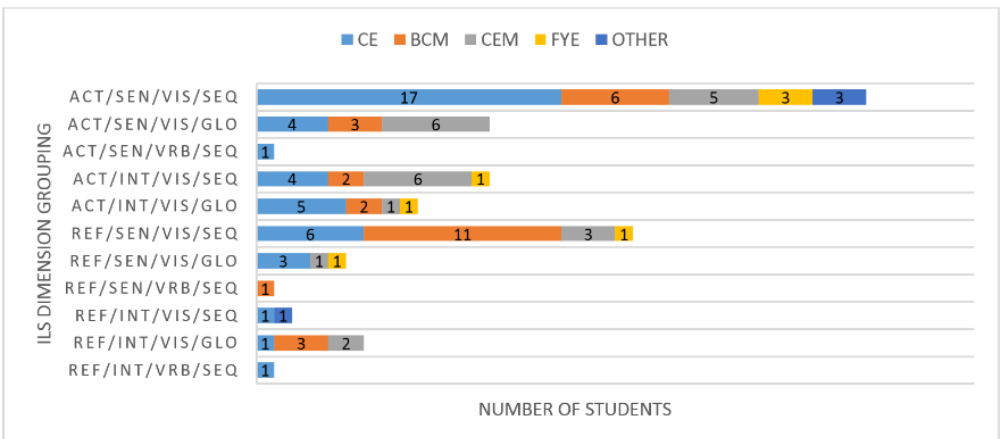

Fig 7. Distribution of high spatial ability students per major by ILS dimension grouping

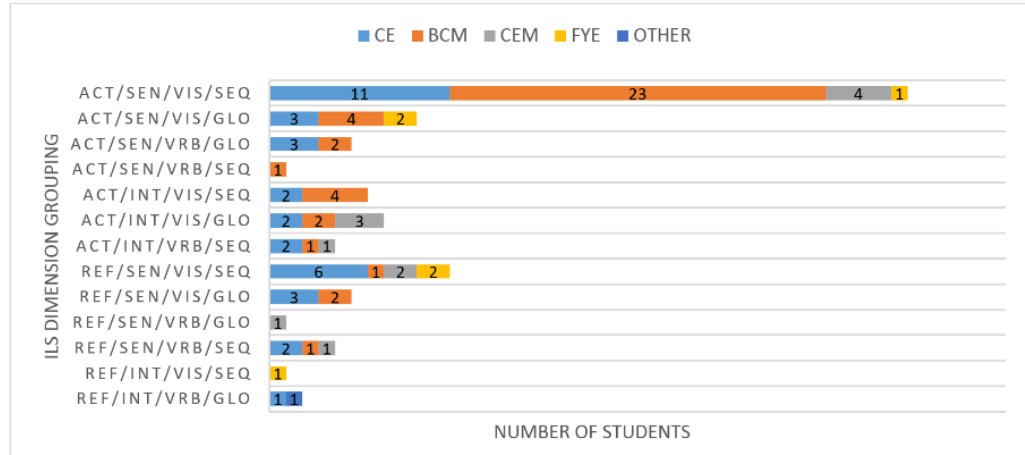

Fig 8. Distribution of low spatial ability students per major by ILS dimension grouping 
It was observed that within the groupings under high and low spatial ability, the ACT/SEN/VIS/SEQ showed a relatively equal number of students. The REF/SEN/VIS/SEQ also stood out in the high spatial ability grouping, with more than 21 students. However, within the low spatial ability grouping, apart from the ACT/SEN/VIS/SEQ, the remaining groups had $<12$ students each.

Next, the ILS dimensions groupings that had sample sizes greater than 6 were selected from the 15 combinations found. Groups with sample sizes less than 6 were removed from this portion of the analysis because they did not provide enough information to determine normalcy of the results obtained for comparison with the other groups. The range of preferences for the 6 groups can be seen in figure 9 .

These selected groups with sample sizes, $\mathrm{n}>6$, were then run through a one-way ANOVA and 2 sample t-test with an alpha $(\alpha)$ level of 0.05 , to determine if there was any significant difference present between the group PSVT means. A summary of the data for these groups, as well as a plot of their means can be found in table 3 and figure 10 respectively.

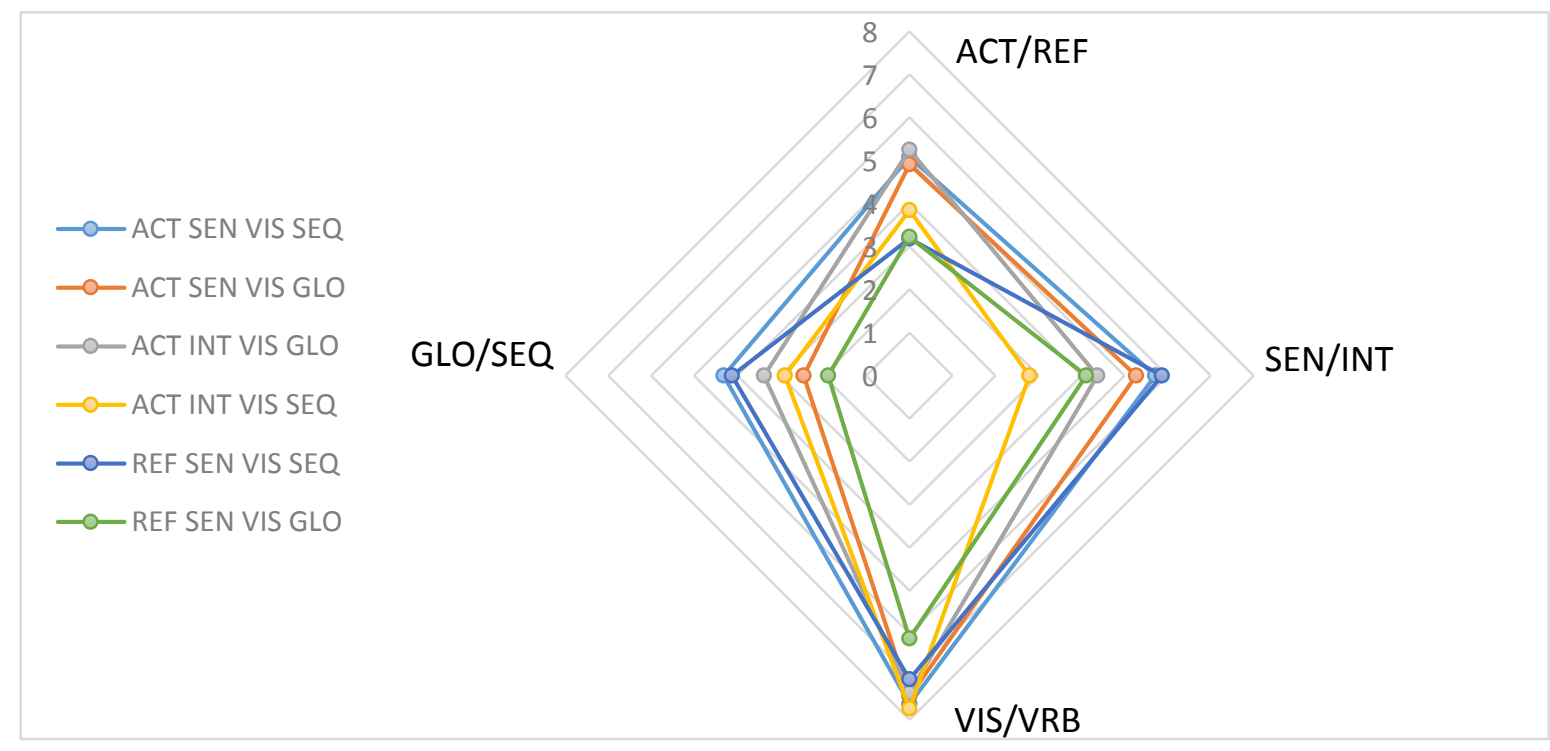

Fig 9. Selected ILS dimension groupings 


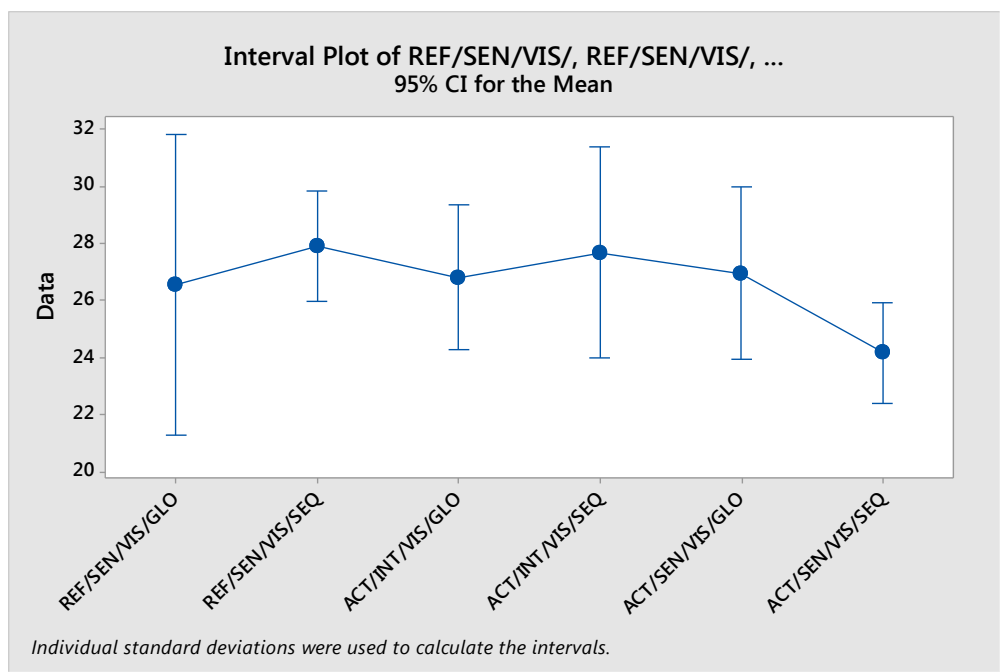

Fig 10. Plot of ILS dimension groupings by PSVT score averages

Table 3. Summary of PSVT data by ILS grouping

\begin{tabular}{|c|c|c|c|c|}
\hline Group & Mean & $\mathrm{N}$ & STDev & $95 \% \mathrm{CI}$ \\
\hline REF/SEN/VIS/GLO & 26.56 & 9 & 6.84 & $(21.30,31.81)$ \\
\hline REF/SEN/VIS/SEQ & 27.906 & 32 & 5.336 & $(25.982,29.830)$ \\
\hline ACT/INT/VIS/GLO & 26.81 & 16 & 4.75 & $(24.28,29.34)$ \\
\hline ACT/INT/VIS/SEQ & 27.68 & 19 & 7.71 & $(23.97,31.40)$ \\
\hline ACT/SEN/VIS/GLO & 26.95 & 22 & 6.84 & $(23.92,29.99)$ \\
\hline ACT/SEN/VIS/SEQ & 24.164 & 73 & 7.544 & $(22.404,25.925)$ \\
\hline
\end{tabular}

An ANOVA test for equal means, yielded a p-value of 0.125. This indicated that there was no significant difference between the overall scores obtained by each of these groups.

Further tests revealed no significance between groups when the scores were limited to the individual sections of the PSVT. There was however, a significant difference between the group scores on the developments section (p-value of 0.028) of the PSVT as shown in table 4.

Table 4. ILS dimensions grouping by PSVT section

\begin{tabular}{|c|c|c|c|c|c|c|c|}
\hline & $\begin{array}{c}\text { REF/SEN/ } \\
\text { VIS/GLO }\end{array}$ & $\begin{array}{c}\text { REF/SEN/ } \\
\text { VIS/SEQ }\end{array}$ & $\begin{array}{c}\text { ACT/INT/ } \\
\text { VIS/GLO }\end{array}$ & $\begin{array}{c}\text { ACT/INT/ } \\
\text { VIS/SEQ }\end{array}$ & $\begin{array}{c}\text { ACT/SEN/ } \\
\text { VIS/GLO }\end{array}$ & $\begin{array}{c}\text { ACT/SEN/ } \\
\text { VIS/SEQ }\end{array}$ & P-value \\
\hline Dev means & 8.556 & 9.813 & 10 & 9.579 & 9.682 & 8.315 & 0.028 \\
\hline Rot Means & 9.556 & 9.188 & 8.875 & 9.211 & 9.136 & 7.877 & 0.091 \\
\hline View Means & 8.44 & 8.906 & 7.938 & 8.895 & 8.136 & 7.973 & 0.763 \\
\hline $\mathrm{N}$ & 9 & 32 & 16 & 19 & 22 & 73 & \\
\hline
\end{tabular}

\section{$\underline{\text { Test for correlation }}$}

The Pearson's correlation coefficient test was run to determine whether any direct correlations were apparent. The table below contains the results of this test.

Overall, no strong correlations were found - although, a number of correlations were found to have significant $\mathrm{p}$ values, yet displayed weak positive and negative correlations between the 
PSVT total and VIS; as well as the VRB and PSVT total. Although the p-value showed significance, this does not necessarily imply practicality.

Table 5. Pearson Correlation test results

\begin{tabular}{|l|l|l|l|l|l|l|l|l|}
\hline & ACT & REF & SEN & INT & VIS & VRB & SEQ & GLO \\
\hline REF & -0.528 & & & & & & & \\
& 0.000 & & & & & & & \\
\hline SEN & 0.020 & 0.0002 & & & & & & \\
& 0.785 & 0.977 & & & & & & \\
\hline INT & -0.027 & -0.003 & -0.515 & & & & & \\
& 0.712 & 0.962 & 0.000 & & & & & \\
\hline VIS & 0.152 & -0.183 & 0.023 & -0.023 & & & & \\
& 0.036 & 0.011 & 0.755 & 0.752 & & & & \\
\hline VRB & 0.024 & 0.027 & -0.043 & 0.058 & -0.421 & & & \\
& 0.740 & 0.714 & 0.551 & 0.420 & 0.000 & & & \\
\hline SEQ & -0.022 & -0.027 & 0.328 & -0.255 & 0.048 & -0.035 & & \\
& 0.759 & 0.709 & 0.000 & 0.000 & 0.510 & 0.631 & & \\
\hline GLO & 0.109 & 0.014 & -0.152 & 0.271 & 0.044 & 0.141 & -0.467 & \\
& 0.133 & 0.848 & 0.036 & 0.000 & 0.540 & 0.051 & 0.000 & \\
\hline PSVT & -0.084 & 0.102 & -0.118 & 0.064 & 0.232 & -0.239 & -0.083 & 0.043 \\
& 0.248 & 0.159 & 0.102 & 0.375 & 0.001 & 0.001 & 0.250 & 0.552 \\
\hline
\end{tabular}

Cell Contents: Pearson Correlation

P-Value

\section{Gender differences for PSVT Sections}

To check for gender differences in the PSVT scores for females and males, an independent 2sample t-test was conducted on the data. Figure 11 shows the distribution of the scores between the genders.

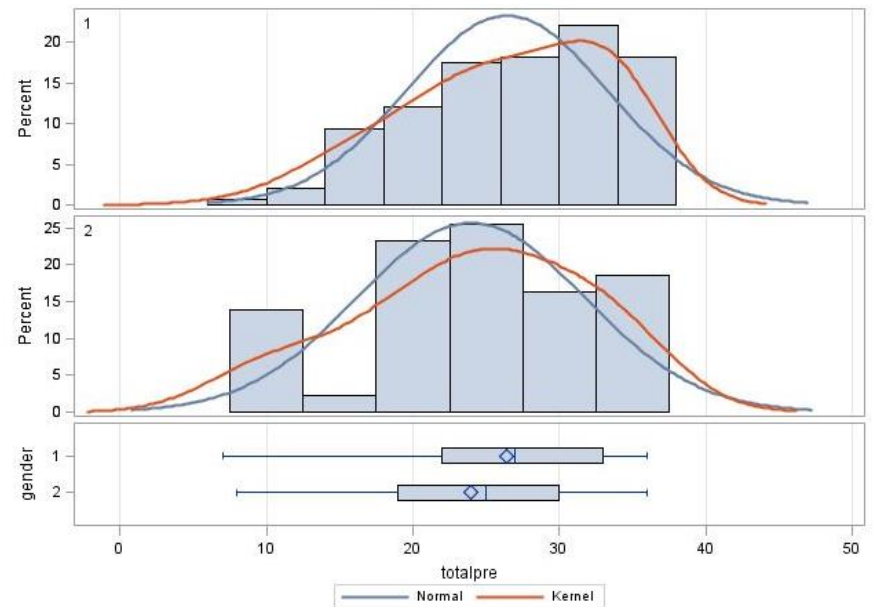

Note: 1 -Male; 2 - Female

Fig 11. Distribution of PSVT scores for males and females

It was observed that the p-value for the t-test was approaching significance, with a value of 0.066 at a $95 \%$ confidence level. Although not statistically significant, digging deeper and slicing by PSVT sections revealed significance on one of the sections of the PSVT between males and females. The results are provided in table 6 . 
Table 6. PSVT scores t-tests by section for gender

\begin{tabular}{|l|l|l|l|}
\hline \multicolumn{1}{|c|}{ Section } & P-value & \multicolumn{1}{c|}{$\begin{array}{c}\text { Mean } \\
\text { (Males) }\end{array}$} & Mean (Females) \\
\hline Overall PSVT & 0.066 & 26.43 & 23.98 \\
\hline Developments & 0.0814 & 9.13 & 9.02 \\
\hline Rotations & 0.090 & 8.80 & 7.91 \\
\hline Views & 0.016 & 8.50 & 7.05 \\
\hline
\end{tabular}

As seen above, a p-value of 0.08 indicated that there was no significant difference between the scores of the females and the males on the Developments section of the PSVT. Moreover, although the rotations section of the PSVT showed slightly larger differences in the PSVT scores between females and males, this difference was also not significant. This is confirmed by the pvalue of 0.09 .

However, the Views section of the PSVT, which measures the spatial orientation factor of spatial visualization showed significant differences in the scores between females and males. A p-value of 0.016 at a $95 \%$ confidence level is clear indication of their significance.

Gender differences of scores grouped by learning style were calculated for PSVT scores grouped by learning style. There were no significant differences found between male and female except for the active and sensing groups, which had p-values of 0.018 and 0.058 respectively. In both the cases the males performed better on the PSVT.

Table 7. PSVT averages for individual ILS dimensions by gender

\begin{tabular}{|l|l|l|l|l|l|l|l|l|}
\hline & ACT & REF & SEN & INT & VIS & VRB & SEQ & GLO \\
\hline Male PSVT Avg & 25.925 & 27.714 & 26.105 & 27.49 & 26.585 & 23.29 & 26.063 & 27.54 \\
\hline Female PSVT Avg & 21.93 & 27.80 & 22.90 & 26.21 & 24.74 & 18.20 & 22.43 & 25.75 \\
\hline P-value & 0.018 & 0.964 & 0.058 & 0.554 & 0.179 & 0.292 & 0.067 & 0.315 \\
\hline
\end{tabular}

\section{Difference in experience}

As there were 28 students who had prior experience with spatial visualization, basic descriptive statistics for these students was checked, and a t-test was run on the two groups.

Table 8. PSVT averages for students with and without prior experience

\begin{tabular}{|c|c|c|c|c|c|}
\hline & $\mathrm{N}$ & Mean & STDev & Min & Max \\
\hline Prior experience & 28 & 30.29 & 5.82 & 26.5 & 36 \\
\hline No experience & 164 & 25.128 & 7.06 & 20 & 36 \\
\hline
\end{tabular}

As presumed, the students with prior experience did well on the PSVT. A high mean of 30.29 was noted, while the students with no prior experience spatial visualization did not do as well, with a mean of 25.13. The large difference in the means helps in understanding the difference in the scores between the two groups as shown in the t-test between the two samples in table 8 . The t-test yielded a p-value $<0.0001$, which implied - as expected - that the difference in means was significant. 


\section{$\underline{\text { Discussion }}$}

When it came to overall performance on the PSVT, it was noted that even though more students in the Building Construction Management Technology (BCM) major scored above $70 \%$ on the PSVT (figure 2), the mean of their total scores showed that the BCM students did significantly worse on average on the PSVT (figure 3) as compared with the other majors. This might be due to the fact that the majority of students sampled in BCM were freshmen, and those of Civil Engineering (CE) and Construction Engineering Management (CEM) were dominated by sophomores (figure 1). This could imply that the longer students studied, the better their spatial abilities were.

Upon observing the results of the Felder-Soloman ILS test, it was seen that the majority of the students sampled had the learning preference of Active (ACT) over Reflective (REF); Sensing (SEN) over Intuitive (INT); Visual (VIS) over Verbal (VRB); and Sequential (SEQ) over Global (GLO). This combination is one that is typical for engineering students ${ }^{28}$ however it was noted that the ACT/SEN/VIS/SEQ dimension grouping dominated overall, as well as within in each major (figure 5 and 6). As one of the main end goals within the construction industry is to turn 2D concepts into reality in our (3D) world, visual and hands on learning that deals with facts in a logical manner is thus a naturally fitting and more effective learning tendency for students aiming to enter into this industry.

When the PSVT scores were divided into high and low, and then grouped by the ILS dimensions, it was observed that there was an even spread of students in the various groups for the levels of high and low spatial ability. No discernable pattern emerged. Moreover, there was no significance between the overall PSVT scores obtained across ILS dimension grouping. This indicates that although students may appear to have strong preference for one dimensions or the other, no single dimension could be said to have the upper hand over the other when it came to the student's inherent spatial ability. It was noted, however, that when the data was sliced and compared by PSVT sections, there was a significant difference in means between the 6 ILS dimension groupings on the PSVT Developments section (see table 5). The developments portion of the PSVT requires students to mentally put back together an object that has been unfolded. According to Bodner and Guay ${ }^{33}$, the PSVT was developed on the premise that "spatial tests that maximize gestalt processing while minimizing analytic processing are the best measures of spatial ability" (p. 7).

It could be argued as to whether having a stronger preference for the visual and global learning style could potentially aid students in completing this task, as thinking holistically is a trait associated with global learning preference. However due to the interacting nature of the dimensions, varying sample sizes, and lack of representation of all the ILS dimension grouping combinations, it is out of the scope of this research to determine the veracity of this assertion. The ILS could not be used to predict spatial ability, much in the same way it could not be used to predict success or failure rates in academic performance ${ }^{25}$.

The Pearson's correlation test showed that the visual and verbal preferences had a slightly significant positive and negative impact, respectively, on the PSVT scores. However, the values although significant, were too small to imply an actual practical impact on the PSVT. It was thus 
concluded that there was no direct correlation between the student's spatial skills and learning preference. Keefe ${ }^{35}$ described learning styles as being "relatively stable indicators of how learners perceive, interact with and respond to the learning environment." Similarly, Felder and Spurlin $^{27}$ emphasize that learning styles "suggest behavioral tendencies rather than being infallible predictors of behavior” (p. 104).

This indicates that although students may appear to have strong preference for one dimensions or the other, it does not completely seclude them from adopting and applying the practices of the other dimensions in order to learn. Learning styles best serve as a guide to better understand how an individual is able to absorb information. However, using the concept of learning style alone to determine learning ability is presumptuous. It is well known that several external factors contribute to each individual's ability to learn, such as interest, background and talent; moreover, the content of material being presented or taught also plays a role in the ability of students to learn ${ }^{36}$. Thus, just as spatial skills can be improved through training, exposure to different problem solving situations and environments could lead to an individual adapting and extending their learning style as they develop ${ }^{37}$.

Traditionally, males have been known to outperform females on spatial ability tests ${ }^{8}$. The idea of performing better on spatial tests involves the ability to manipulate and maintain objects in the mind, and one school of thought espouses that males perform better on spatial ability tests compared to females due to evolution, as described in the Hunter-Gatherer theory ${ }^{38}$. In this study, a similar trend was noted, however unequal sample sizes played an important role. Although the overall PSVT scores between males and females did not show a significant difference (table 6), it was nonetheless interesting to note the differences present in each section on the PSVT between the genders.

The first two sections (developments and rotations) did not show any significant differences in performance between the males and the females. It is possible that a higher sample size would've projected those differences, but this remains to be seen. Typically, differences in spatial ability have been noted in the mental rotations skills. However, was not the case here as the third section (views), showed a significant difference in the scores based on gender. The Views section of the PSVT emphasizes the ability to view an object from different angles. It would be interesting to see if the differences still exist with equal sample sizes.

\section{$\underline{\text { Conclusion }}$}

This research has been an attempt to explore the relationship between learning style preferences and spatial visualization skills of construction related majors in engineering and technology using the PSVT and Felder-Soloman ILS tests. The results - although showing some interesting outcomes - indicated overall that there was no direct correlation between the learning style of the students and their spatial visualization ability at that point in time.

In conclusion, this paper brings to light the fact that the results from the ILS have no relation to an individual's spatial visualization. Thus, a student's learning style in itself cannot be said to predict their aptitude or strength for spatial visualization tasks. Although spatial visualization 
ability is often developed over a period of time, some individuals are born with high spatial ability. Various factors are involved in developing an individual's spatial visualization ability, however it seems that an individual's learning style may not be one of them. Using a different learning style test might perhaps help in understanding this relation better.

For future research, it would be interesting to see the rate of improvement of spatial visualization skills those classified as having low spatial ability would have at the end of the semester after having been exposed to the formal training; while observing which learning style group makes the most gain.

\section{References}

1. Connolly, P. (2009). Spatial ability improvement and curriculum content. Engineering Design Graphics Journal, 73(1).

2. Carroll, J. B. (1993). Human cognitive abilities: A survey of factor-analytic studies. New York: Cambridge University Press.

3. McGee, M. G. (1979). Human spatial abilities: Psychometric studies and environmental, genetic, hormonal, and neurological influences. Psychological Bulletin, 86(5), 889-918.

4. Vandenberg, G., Kuse, R., \& Vogler, P. (1985). Searching for correlates of spatial ability. Perceptual and Motor Skills, 60, 343-350.

5. Harle, M. \& Towns, M., (2010), A Review of Spatial Ability Literature, Its Connection to Chemistry, and Implications for Instruction. J. Chem. Educ., 2011, 88 (3), pp 351-360

6. Thurstone, L. (1950). Some primary abilities in visual thinking. Chicago, IL: University of Chicago Psychometric Lab Report No. 59. Psychological Bulletin, 86(5), 889-918.

7. Sorby, S., \& Baartmans, B. (2000). The development and assessment of a course for enhancing the 3-D spatial visualization skills of first year engineering students. Journal of Engineering Education, 89(3), 301-307.

8. Hsi, S., Linn, M., \& Bell, J. (1997). The role of spatial reasoning in engineering and the design of spatial instruction. Journal of Engineering Education, 86(2), 151-158.

9. Miller, C., \& Bertoline, G. (1991). Spatial visualization research and theories: Their importance in the development of an engineering and technical design graphics curriculum model. Engineering Design Graphics Journal, 55(3), 514.

10. Dunn, R. (1984). Learning style: State of the science. Theory into practice, 23(1), 10-19.

11. Coffield, F., Moseley, D., Hall, E., \& Ecclestone, K. (2004). Learning styles and pedagogy in post 16 learning: a systematic and critical review. The Learning and Skills Research Centre.

12. Curry, L. (1983). An Organization of Learning Styles Theory and Constructs. Retrieved from: http://files.eric.ed.gov/fulltext/ED235185.pdf

13. Gregorc, A. F. (1985). Gregorc style delineator: A self-assessment instrument for adults. Gregorc Assoc.

14. Herrmann, N. (1995). Creative problem solving.

15. Dunn, R., Dunn, K., \& Price, G. (1989). Learning style inventory (LSI). Price Systems, Incorporated (PO Box 1818, Lawrence 66044).

16. Rogowsky, B., Calhoun, B., \& Tallal, P. (2015). Matching learning style to instructional method: Effects on comprehension. Journal of Educational Psychology, 107(1), 64.

17. Felder, R. M., \& Silverman, L. K. (1988). Learning and teaching styles in engineering education. Engineering education, 78(7), 674-681.

18. Sadowski, M. S., Birchman, J. A., \& Harris, L. V. A. (2009). An Assessment of Graphics Faculty and Student Learning Styles. Engineering Design Graphics Journal, 70(2).

19. Birchman, J. A., \& Sadowski, M. A. (2009). Strategies for bridging learning styles. Engineering Design Graphics Journal, 71(1).

20. Sharp, J. E., Harb, J. N., \& Terry, R. E. (1997). Combining Kolb learning styles and writing to learn in engineering classes. Journal of Engineering Education, 86(2), 93-101. 
21. Schall, M. C., Rusch, M. L., Thomas, G., \& Lee, J. D. (2011, September). An Investigation of Learning Style and Discipline in a Human Factors Course. In Proceedings of the Human Factors and Ergonomics Society Annual Meeting (Vol. 55, No. 1, pp. 555-559). SAGE Publications.

22. Harris, L. V. A., Sadowski, M. S., \& Birchman, J. A. (2009). A comparison of learning style models and assessment instruments for university graphics educators. Engineering Design Graphics Journal, 70(1).

23. Buch, K., \& Sena, C. (2001). Accommodating diverse learning styles in the design and delivery of on-line learning experiences. International Journal of Engineering Education, 17(1), 93-98.

24. Cagiltay, N. E. (2008). Using learning styles theory in engineering education. European Journal of Engineering Education, 33(4), 415-424.

25. Van Zwanenberg, N., Wilkinson, L. J., \& Anderson, A. (2000). Felder and Silverman's Index of Learning Styles and Honey and Mumford's Learning Styles Questionnaire: how do they compare and do they predict academic performance?. Educational Psychology, 20(3), 365-380.

26. Guay, R. (1977). Purdue Spatial Visualization Tests; Purdue Research Foundation: West Lafayette, IN

27. Felder, R., \& Spurlin, J. (2005). Applications, reliability and validity of the index of learning styles. International journal of engineering education, 21(1), 103-112.

28. Zywno, M. (2003). A contribution to validation of score meaning for Felder-Soloman's index of learning styles. In Proceedings of the 2003 American Society for Engineering Education annual conference \& exposition(Vol. 119, No. 1-5)

29. Litzinger, T. A., Lee, S. H., Wise, J. C., \& Felder, R. M. (2007). A psychometric study of the index of learning styles@. Journal of Engineering Education, 96(4), 309-319.

30. Litzinger, T. A., Lee, S. H., \& Wise, J. C. (2005). A study of the reliability and validity of the Felder-Soloman Index of Learning Styles. In Proceedings of the 2005 American Society for Education Annual Conference \& Exposition (pp. 1-16).

31. Cook, D. A., \& Smith, A. J. (2006). Validity of index of learning styles scores: multitrait- multimethod comparison with three cognitive/learning style instruments. Medical Education, 40(9), 900-907.

32. Felder, R., \& Brent, R. (2005). Understanding student differences. Journal of engineering education, 94(1), 57-72.

33. Kolb, D. (1984) Experiential learning: experience as the source of learning and development (Englewood Cliffs, NJ, Prentice-Hall)

34. Bodner, G., \& Guay, R. (1997). The Purdue visualization of rotations test. The Chemical Educator, 2(4), 1-17.

35. Keefe, J. (1979). Learning style: An overview. Student learning styles: Diagnosing and prescribing programs, 1, 117.

36. Riener, C., \& Willingham, D. (2010). The myth of learning styles. Change: The magazine of higher learning, 42(5), 32-35.

37. Reid, J. M. (1987). The learning style preferences of ESL students. TESOL quarterly, 21(1), 87-111.

38. Silverman, I., Choi, J., \& Peters, M. (2007). The hunter-gatherer theory of sex differences in spatial abilities: Data from 40 countries. Archives of sexual behavior, 36(2), 261-268. 